${ }^{12}$ Araújo, A.L.A.; Ohara, M.T. Qualidade microbiológica de drogas vegetais comercializadas em feiras de São Paulo e de infusos derivados. Revista Brasileira de Ciências Farmacêuticas, v. 36, n. 1, jan./jun., p. 129-136, 2000.

${ }^{13}$ Brandão, M.G.L.; Oliveira, P.; Moreira, R.A.; Alves, R.M.S.; Vieira, M.T.; Moreira-Campos, L.M. Qualidade de amostras comerciais de plantas medicinais e produtos fitoterápicos: drogas inscritas na Farmacopéia Brasileira. Infarma, v. 13, n. 11/12, p. 60-61, 2001.

${ }^{14}$ Barbosa, M.C.S.; Beletti, K.M.S.; Corrêa, T.F.; Santos, C.A.M. Avaliação da qualidade de folhas de boldo-do-chile (Peumus boldus Molina) comercializadas em Curitiba, PR. Revista Brasileira de Farmacognosia, v. 11, n. 1, p. 1-4, 2001.

15 Instituto de Produção e Renda. Coordenadoria de Comercialização, Departamento de Gestão de Mercado. São Luís, 1999.

${ }^{16}$ Moura, R.A.; Wada, C.S.; Purchio, A.; Almeida, T.V. Técnicas de laboratório. 3. ed. São Paulo: Livraria Atheneu, p. 511, 1992.

${ }^{17}$ Trabulsi, L.R. (ed.). Microbiologia. 2. ed. São Paulo: Atheneu, p. 386, 1996.

${ }^{18}$ Konemann, E.W.; Allen, S.D.; Janda, W.M.; Schreckenberger, P.C.; Winn, W.C. Diagnóstico microbiológico: texto e atlas colorido. 5. ed., São Paulo: Panamericana, 1999.

*Autor para corespondência:

Profa. Flavia Maria Mendonça do Amaral

Departamento de Farmácia - Centro de Ciências

Biológicas e da Saúde

Universidade Federal do Maranhão

Rua Treze de Maio, 506 - Centro - CEP 65.010-600

São Luís (MA)

E-mail: fmman@zaz.com.br

\section{Avaliação da qualidade de matérias-primas de ruibarbo utilizadas em formulações farmacêuticas}

\author{
Sousa, O.V.*; Oliveira, M.S.; Cunha, R.O.; Costa, B.L.S.; \\ Zancanella, C.R.; Leite, M.N.
}

Departamento Farmacêutico, Faculdade de Farmácia e Bioquímica, Universidade Federal de Juiz de Fora

\section{Resumo}

As plantas denominadas de ruibarbo sintetizam antraquinonas e taninos, que são responsáveis pelos efeitos laxante e adstringente, respectivamente. Análises da qualidade de cinco matérias-primas de ruibarbo foram realizadas a fim de detectar adulterações. As reações para antraquinonas e taninos foram positivas. Os constituintes rapônticos foram observados na amostra de Rheum palmatum (2). As medidas de cinzas totais para Rheum palmatum (2) e Ferraria cathartica estão acima do esperado. Conforme resultados, as amostras de Rheum palmatum (2) e Ferraria cathartica devem estar adulteradas.

\begin{abstract}
Plants known as rhubarb synthesize anthraquinones and tannins. Theses compounds have medicinal uses as laxative and astringent, respectivity. The quality of five raw materials was analysed to detect adulterant. Anthraquinones and tannins reactions were positive. Derivatives rhapontocoside were observed in the sample of Rheum palmatum (2). Total ashes were increased to Rheum palmatum (2) and Ferraria cathartica. According to the results, samples of Rheum palmatum (2) and Ferraria cathartica shoulde are adulterated.
\end{abstract}

O ruibarbo é uma droga fitoterápica empregada contra diversos distúrbios, principalmente das funções do estômago e fígado, sendo considerado como excelente tônico e purgante. Também é utilizado na medicina veterinária nos casos de icterícia em cães e vitelas ${ }^{7,12,13}$. É preparado em formas farmacêuticas como infusões, decocções e tinturas, assim como na forma de vinho ou marmelada, dependendo da finalidade ${ }^{2}$.

Os constituintes químicos encontrados no ruibarbo responsáveis pelos efeitos terapêuticos são descritos como derivados antracênicos e taninos. As hidroximetilantraquinonas oscilam entre 2 a $5 \%$, podendo atingir até 7,5\%. Os taninos formam outro grupo característico do ruibarbo que, por hidrólise, 
originam a glicose e o ácido gálico. Os taninos aproximam-se dos $5 \%$ 1,3,4,8,9,10,12.

A espécie Rheum rhaponticum cultivada na Europa, porém de origem asiática, é quimicamente semelhante ao ruibarbo da China. Este contém diversas substâncias antraquinônicas, tais como crisofanol, emodina e seu monoglicosídeo e a glicocrisarona $a^{3,414,15}$. O constituinte característico é a raponticina, um monoglicosídeo do 3,5,3-trihidroxi-4-metoxiestilbeno que, por hidrólise, resulta em glicose, raponticogenol ou rapontigenina. A raponticina é encontrada em diversas espécies de ruibarbo europeus, não ocorrendo em espécies oficiais. Nos rapônticos, há sempre uma quantidade inferior de constituintes antraquinônicos do que nas espécies oficiais, o que torna sua ação purgativa menor ${ }^{1,14,15}$.

Os rapônticos são reconhecidos pelos caracteres microscópicos, em particular pela forma de raios medulares e pela ausência de estrelas. Examinadas à luz de Wood apresentam fluorescência violeta em contraste com a do ruibarbo oficial, de cor castanho escurecida ${ }^{1,15}$.

Nos últimos anos, houve um crescimento significativo do mercado de fitoterápicos e plantas medicinais no Brasil, o que acarretou a busca da validação analítica dos produtos comercializados. Além disso, foram observados abusos, tais como adulteração de espécies e matérias-primas vegetais. Por exemplo, é comum a espécie Rheum rhaponticum ser comercializada como ruibarbo oficial ou ser misturada com outras espécies. Isso significa que a sociedade está consumindo um produto adulterado. Com intuito de verificar a existência de algum tipo de adulteração, cinco amostras de matérias-primas de ruibarbo comercializadas em farmácias de produtos naturais de Juiz de Fora (MG) foram analisadas.

Análise das características organolépticas: As matérias-primas analisadas foram constituídas de um pó finíssimo amarelo alaranjado a pardo amarelado, com odor característico, aromático, um pouco amargo e adstringente. Esse pó era bem homogêneo por todo sua extensão. Um extrato aquoso foi obtido a partir do contato com água, mostrando ter constituintes solúveis nas amostras. No que refere às características organolépticas, as matérias-primas analisadas estavam de acordo com as especificações das farmacopéias e literatura.

Avaliação de cinzas totais, umidade e pH: Os teores de cinzas totais nas amostras analisadas variaram de 11,94 $\pm 0,12$ a 13,84 \pm 0,16 , enquanto os da umidade ficaram entre $6,47 \pm 0,30$ e $8,17 \pm$ 0,11 (tabela 1 ). Os valores de cinzas totais acima de $13 \%$ observados na tabela 1 para Rheum palmatum(2) e Ferraria cathartica possivelmente se devem à contaminação produzida por outros produtos ou processo de pós-colheita inadequado para remoção dos contaminantes provenientes do cultivo. Conforme estabelecido nas diferentes farmacopéias, o teor de umidade pode variar de 8 a 14\%, o que favorece a integridade das amostras. Dessa forma, os valores obtidos de umidade nessa pesquisa estão de acordo com as especificações.

$\mathrm{O}$ pH das diferentes amostras variou de 4,71 $\pm 0,02$ a $6,39 \pm 0,03$, demonstrando que as espécies de ruibarbo possuem pH ácido (tabela 1). É observado também que, as amostras contendo constituintes rapônticos são mais ácidas.
Tabela 1. Quantificação de cinzas totais, umidade e $\mathrm{pH}$ das matérias-primas de ruibarbo analisadas (média \pm dp).

\begin{tabular}{llll}
\hline Amostras & Cinzas Totais & Umidade & $\mathbf{p H}$ \\
\hline Rheum officinalis & $12,94 \pm 0,12$ & $7,67 \pm 0,12$ & $6,39 \pm 0,03$ \\
Rheum palmatum (1) & $12,63 \pm 0,15$ & $8,17 \pm 0,11$ & $6,20 \pm 0,02$ \\
Rheum palmatum (2) & $13,84 \pm 0,16$ & $6,47 \pm 0,30$ & $4,71 \pm 0,02$ \\
Rheum rhaponticum & $11,94 \pm 0,12$ & $6,97 \pm 0,15$ & $4,74 \pm 0,01$ \\
Ferraria cathartica & $13,23 \pm 0,05$ & $8,14 \pm 0,04$ & $5,56 \pm 0,04$ \\
\hline
\end{tabular}

Identificação das drogas sob a luz ultravioleta: Através da análise do material pulverizado e do extrato etanólico impregnado em papel de filtro, as amostras foram observadas sob a luz ultravioleta a $254 \mathrm{~nm}$. O aparecimento da fluorescência violeta indicou a presença de constituintes rapônticos nas espécies Rheum palmatum (2), Rheum rhaponticum e Ferraria cathartica (tabela 2). Diante desse resultado, constatou-se que a amostra de Rheum palmatum (2) constitui uma adulteração, seja por substituição por uma espécie rapôntica ou por uma mistura de espécies de ruibarbo. As amostras de Rheum officinalis e Rheum palmatum (1) não produziram fluorescências, caracterizando-se como ruibarbos oficiais. Esse tipo de avaliação é fundamental para distinguir entre um ruibarbo rapôntico e um oficial.

Tabela 2. Análises das matérias-primas de ruibarbo analisadas sob a luz ultravioleta.

\begin{tabular}{lll}
\hline Amostras & Droga pulverizada & Extrato Impregnado \\
\hline Rheum officinalis & Fluorescência negativa & Fluorescência negativa \\
Rheumpalmatum(1) & Fluorescência negativa & Fluorescência negativa \\
Rheum palmatum (2) & Fluorescência positiva & Fluorescência positiva \\
Rheum rhaponticum & Fluorescência positiva & Fluorescência positiva \\
Ferraria cathartica & Fluorescência positiva & Fluorescência positiva \\
\hline
\end{tabular}

Identificação das drogas por cromatografia de camada fina: Os resultados apresentados nesse item correspondem às amostras de Rheum officinalis, Rheum palmatum (2) e Rheum rhaponticum. É observado na figura 1A, que as amostras de Rheum palmatum (2) e Rheum rhaponticum apresentam os mesmos perfis cromatográficos com o aparecimento de manchas semelhantes e Rfs variando de 0,12 a 0,90. As manchas correspondentes à coloração alaranjada a vermelho indicam antraquinonas e derivados antracênicos e as manchas esverdeadas parecem ser raponticosídeo e genina. Esses resultados demonstram que, possivelmente, o Rheum rhaponticum está sendo comercializado como Rheum palmatum (2), constituindo assim uma adulteração.

O perfil cromatográfico do Rheum officinallis mostrou a presença de 6 manchas de coloração alaranjada à vermelha, com Rfs que variaram de 0,13 a 0,90. Esse perfil está de acordo com o citado na literatura.

Para certificar que o Rheum palmatum (2) constituía uma adulteração do Rheum rhaponticum, placas cromatográficas 
contendo as amostras foram eluídas em acetato de etila:metanol:água (100:13,5:10), usando como revelador o ácido fosfomolíbdico e comparadas com cromatografias citadas na

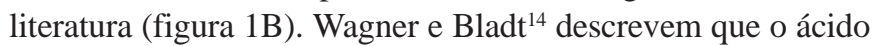
fosfomolíbdico é um revelador mais específico na identificação e diferenciação de Rheum palmatum e Rheum rhaponticum (figuras 1C e 1D). Uma mancha azulada escura com Rf em torno de 0,45 e 0,55 , indica a presença de raponticosídeo/ deoxiraponticosídeo encontrada na espécie de Rheum rhaponticum. Diante do perfil cromatográfico observado na figura $1 \mathrm{~B}$, os constituintes raponticosídeo/deoxiraponticosídeo estão presentes na matéria-prima de Rheum palmatum (2), demonstrando que essa amostra, possivelmente, é uma adulteração do Rheum rhaponticum. Com certeza, a amostra de Rheum palmatum (2) analisada não é a espécie considerada oficial.

Na figura 1B é também observado que no perfil cromatográfico do Rheum officinalis não foram detectadas manchas de coloração verde azulada escura, demonstrando ser de fato uma espécie oficial.

Pesquisa de antraquinonas: A tabela 3 mostra os resultados das reações de Borntraeger para as amostras de ruibarbo analisadas. As antraquinonas produziram reação positiva através da coloração amarelada da camada etérea, enquanto as antraquinonas livres promoveram coloração rósea a vermelha na camada aquosa. A presença de glicosídeos antraquinônicos na forma de O-heterosídeos foi observada pela coloração castanha adquirida na fase alcalina. Não foi detectada a presença de C-heterosídeos.
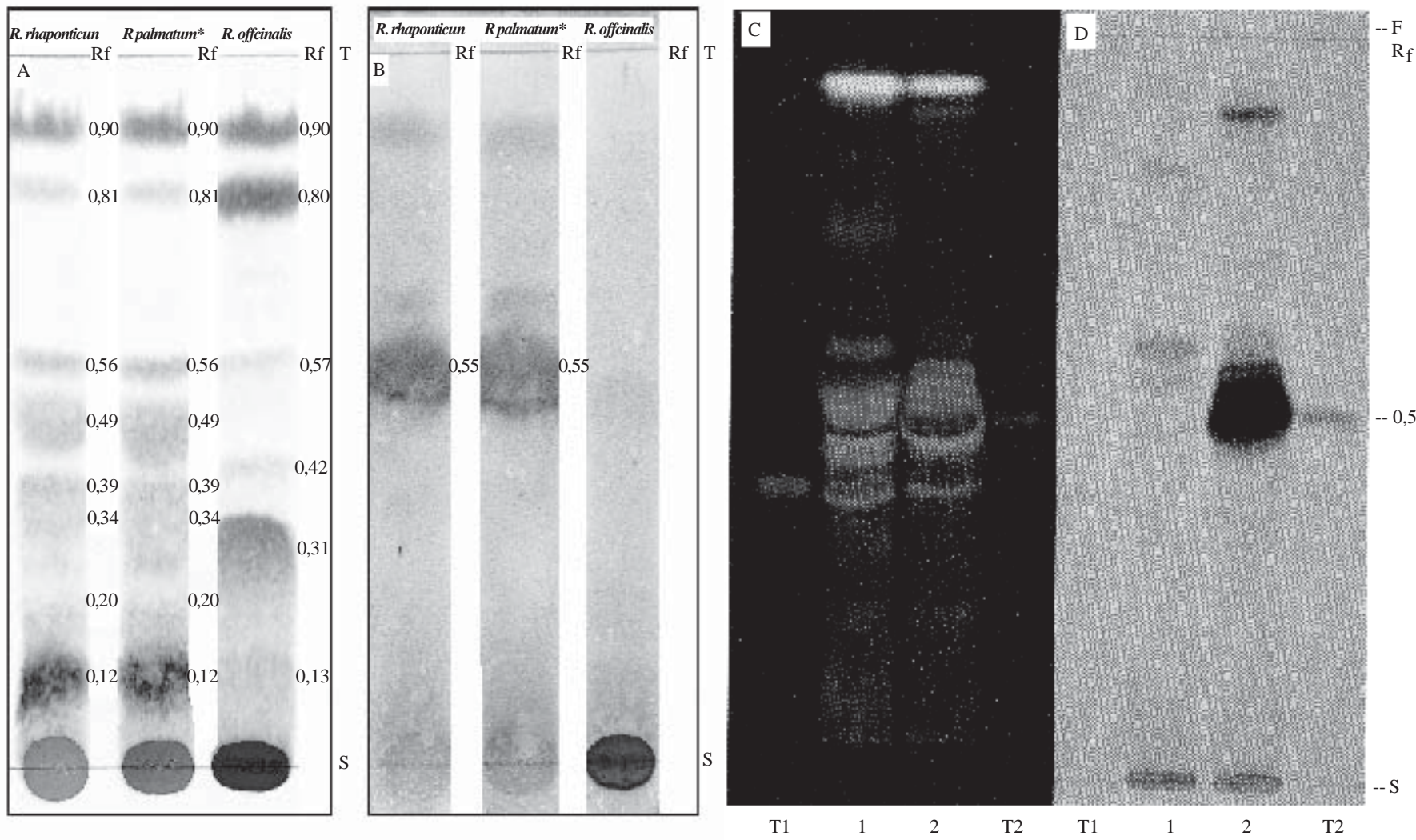

Figura 1. Perfis cromatográficos comparativos de extratos alcoólicos de amostras de ruibarbo, tendo como eluente

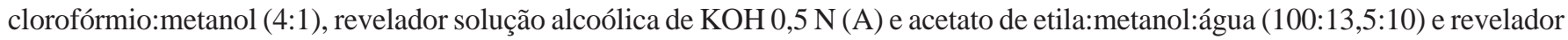
reagente fosfomolíbdico (B). Figuras 1C e 1D obtidas de Wagner e Bladt ${ }^{14}$.

* Matéria-prima comercializada como Rheum palmatum (2).

Tabela 3. Pesquisa de antraquinonas pela reação de Borntraeger em matérias-primas de ruibarbo.

\begin{tabular}{cccccc}
\hline $\begin{array}{c}\text { Reações } \\
\text { de Borntraeger }\end{array}$ & $\begin{array}{c}\text { Rheum } \\
\text { officinalis }\end{array}$ & $\begin{array}{c}\text { Rheum } \\
\text { palmatum (1) }\end{array}$ & $\begin{array}{c}\text { Rheum } \\
\text { palmatum (2) }\end{array}$ & $\begin{array}{c}\text { Rheum } \\
\text { rhaponticum }\end{array}$ & $\begin{array}{c}\text { Ferraria } \\
\text { cathartica }\end{array}$ \\
\hline Antraquinonas & Positiva & Positiva & Positiva & Positiva & Positiva \\
Antraquinonas livres & Positiva & Positiva & Positiva & Positiva & Positiva \\
O-heterosídeos & Positiva & Positiva & Positiva & Positiva & Positiva \\
C-heterosídeos & Negativa & Negativa & Negativa & Negativa & Positiva \\
\hline
\end{tabular}


As substâncias aglicônicas e os respectivos heterosídeos comportam-se no ensaio de Borntraeger de maneira diferente em solução e em presença de reagente alcalino, como revelam as cores das soluções obtidas. As substâncias 1,8hidroxiantraquinônicas exercem efeito mesomérico acentuado, decorrentes dos grupos carbonilas. Este estado de mesomeria é alcançado pela formação de uma ponte de hidrogênio, resultado de um sistema de quatro anéis. Em solução, as moléculas absorvem a luz num comprimento de onda próximo a $430 \mathrm{~nm}$, possuindo cor amarela-laranja. A cor vermelha observada na reação de Borntraeger deve-se à ionização das hidroxilas fenólicas, o que produz uma maior ressonância molecular. Os máximos de absorção deslocam-se no sentido dos maiores comprimentos de onda (cerca de $520 \mathrm{~nm}$ ) e as soluções alcalinas mostram-se coradas de vermelho 3 ,4.

Nos monoglicosídeos, em virtude de uma hidroxila se encontrar bloqueada, diminui o efeito mesomérico, assim o máximo de absorção retrocede para menores comprimentos de onda (cerca de $490 \mathrm{~nm}$ ) e a solução aparece corada de laranja avermelhada ${ }^{3,4}$.

Nas antronas, não se acentuam os fenômenos de ressonância e as suas soluções dão com os álcalis, apenas uma cor amarela. Essa cor, obtida nos ensaios positivos da reação de Borntraeger, desaparece depois da adição de pó de alumínio e de $\mathrm{KOH}$, por terem reduzido as formas oxidadas. Mas, basta agitar o tubo para se reoxidarem ao ar, readquirindo a cor vermelha $^{3,4}$.

Pesquisa de taninos: De acordo com a tabela 4, as reações para detectar a presença de taninos foram positivas para todas as amostras analisadas. Essas reações produziram precipitados verde escuro, marrom tijolo, marrom escuro e branco para sais de ferro, acetato de chumbo, acetato de cobre e alcalóides, respectivamente.

Tabela 4. Pesquisa de taninos em matérias-primas de ruibarbo.

\begin{tabular}{cccccc}
\hline Reaçõe & Rheum officinalis & Rheum palmatum (1) & Rheum palmatum (2) & Rheum rhaponticum & Ferraria cathartica \\
\hline Sais de $\mathrm{Fe}$ & Presença & Presença & Presença & Presença & Presença \\
Acetato de $\mathrm{Pb}$ & Presença & Presença & Presença & Presença & Presença \\
Acetato de $\mathrm{Cu}$ & Presença & Presença & Presença & Presença & Presença \\
Alcalóides & presença & Presença & Presença & Presença & Presença \\
\hline
\end{tabular}

As reações de identificação de taninos podem ser de caráter geral ou de acordo com a maior ou menor especificidade. Geralmente, são próprias dos polifenóis de pesos moleculares baixos, que sempre se encontram em conjunto com os taninos. A reação com alcalóides, por exemplo, é uma das mais características, pelo fato de que os taninos possuem propriedades de serem precipitados em soluções aquosas. Os taninos também reagem com os metais, pelos seus grupos hidroxilas fenólicos e carboxílicos, resultando em complexos geralmente corados, muitas vezes, insolúveis ${ }^{3,4,15}$.

As matérias-primas de Rheum officinalis, Rheum palmatum (1) e Rheum rhaponticum apresentaram características químico-farmacognósticas de acordo com as citadas na literatura. A amostra correspondente à espécie Rheum palmatum (2) produziu propriedades químico-farmacognósticas de ruibarbo rapôntico, constituindo assim, uma adulteração do ruibarbo oficial. Os teores de cinzas totais das matérias-primas de Rheum palmatum (2) e Ferraria cathartica se encontram elevados, o que supõe que essas amostras podem constituir uma adulteração por materiais provenientes de outros produtos ou de procedimentos inadequados pós-colheita. Portanto, é de fundamental importância a avaliação da qualidade das plantas medicinais e fitoterápicos comercializados para fins terapêuticos, de modo que se garanta a eficácia e que a sociedade possa consumir produtos de boa qualidade.

\section{Materiais e Métodos}

Drogas analisadas: As drogas usadas nesse estudo constituíram-se de matérias-primas obtidas de rizomas de espécies de ruibarbo comercializadas em farmácias de produtos naturais de Juiz de Fora (MG), cujos nomes científicos encontrados nas embalagens foram: Rheum officinalis, Rheum palmatum (1), Rheum palmatum (2), Rheum rhaponticum e Ferraria cathartica.

Análise organoléptica, cinzas totais, umidade e pH: As caraterísticas organolépticas foram feitas por análise da cor, do sabor, do odor, da consistência e da solubilidade ${ }^{15}$. A medida de $\mathrm{pH}$ foi realizada a partir de um extrato aquoso obtido de $0,1 \mathrm{~g} / \mathrm{ml}$ da amostra pulverizada, usando-se um pHmetro Mettler Toledo PB3002. O teor de cinzas totais foi feito com $3 \mathrm{~g}$ da droga pulverizada, transferida a um cadinho, previamente calcinado a $600{ }^{\circ} \mathrm{C}$ por $1 \mathrm{~h}$, e incinerando paulatinamente a temperatura de $450{ }^{\circ} \mathrm{C}$ por 4 horas em mufla Nabertherm L3/C66. O teor de umidade foi medido em um sistema de secagem de infra-vermelho SI4040 com balança digital BG200. Nos ensaios de cinzas totais, umidade e $\mathrm{pH}$ foram feitas três medidas.

Identificação das drogas: A identificação das matérias-primas foi realizada com o pó e com extratos alcoólicos das amostras impregnados em papel de filtro sob a luz ultravioleta a $254 \mathrm{~nm}^{5}$. Cromatografias de camada fina contendo extratos hidroalcoólicos (etanol 60\%) das amostras foram eluídas com clorofórmio:metanol (4:1) ou acetato de etila:metanol:água (100:13,5:10) e reveladas, respectivamente, com solução alcoólica de $\mathrm{KOH} 0,5 \mathrm{~N}$ e reagente fosfomolíbdico. Esses procedimentos cromatográficos identificam constituintes antraquinônicos e rapônticos ${ }^{16}$. A pesquisa de antraquinonas foi feita pela reação de Borntraeger, distinguindo as antraquinonas livres e combinadas (O-heterosídeos e C-heterosídeos), enquanto a 
pesquisa de taninos foi feita pelas reações com sais de ferro, com acetato de chumbo, acetato de cobre e com alcalóides ${ }^{5,11,12}$.

\section{Referências}

${ }^{1}$ Bruneton, J. Elementos de fitoquimica y de farmacognosia. $1^{\text {a }}$ ed., Zaragoza, Espanha: Ed. Acribia, p. 189-213, 1991.

${ }^{2}$ Cooper, M.R.; Johnson, A.W. Poisonous plants in Britain and their effects on animals and man. London, England, Her Majesty's Stationery Office, 305p., 1984.

${ }^{3}$ Costa, A. F. Farmacognosia. 4 a ed., Lisboa, Portugal, F. C. G., II V.,p. 248-259, 1994.

${ }^{4}$ Costa, A.F. Farmacognosia. $4^{\text {a }}$ ed., Lisboa, Portugal, F. C. G., I V.,p. 906-959, 1994.

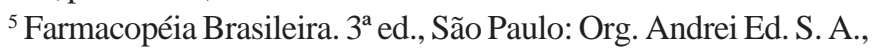
p. 843-845, 1977.

${ }^{6}$ Farmacopéia Brasileira. $4{ }^{\text {a }}$ ed., São Paulo: Atheneu Ed. S. P. Ltda, p. V.5.1., 6.2, 6.3, 1988.

${ }^{7}$ Godding, E.W. Therapeutics of laxative agents with special reference to the anthraquinones. Pharmacology, v. 14, p. 78101, 1976.

${ }^{8}$ Haslam, E. Natural polyphenols (vegetable tannins) as drugs and medicines: possible modes of action. J. Nat. Prod., v. 59, p. 205-515, 1996.

${ }^{9}$ Lemli, J.A.J.M. Chemical assay of anthraquinone drugs. Pharmacology, v. 14, p. 62-72, 1976.

${ }^{10}$ Mann, J. Secondary metabolism. $2^{\mathrm{a} e d .,}$ New York, USA: Oxford Science Publications, 374p., 1987.

${ }^{11}$ Matos, F. J. Introdução a fitoquímica experimental. Fortaleza: Edições UFC, 128p., 1997.

${ }^{12}$ Matos, J.M.D.; Matos, M.E.O. Farmacognosia: curso teóricoprático. $1^{\mathrm{a}}$ ed., Fortaleza: Edições UFC, p. 128-137, 1989.

${ }^{13}$ Nelemans, F. Clinical and toxicological aspects of anthraquinone laxatives. Pharmacology, v. 14, p. 73-77, 1976.

${ }^{14}$ Robbers, J.E.; Speedie, M.K.; Tyler, V.E. Pharmacognosy and pharmacobiotechnology. International ed., Pensylvania, USA: Williams \& Wilkim, 337p., 1996.

${ }^{15}$ Simões, C.M.O.; Schenkel, E.P.; Gosmann, G.; Mello, J.C.P.; Mentz, L.A.; Petrovick, P.R. Farmacognosia: da planta ao medicamento. $2^{\mathrm{a}}$ ed., Porto Alegre/Florianópolis: Ed. UFRGS/ Ed. UFSC, 821p., 2000.

${ }^{16}$ Wagner, H.; Bladt, S. Plant drug analysis: a thin layer chromatography atlas. $2^{\mathrm{a} e d}$., München, Germany, Springer, 384p., 1995.

\section{*Autor para correspondência:}

Prof. Dr. Orlando Vieira de Souza

Departamento Farmacêutico

Faculdade de Farmácia e Bioquímica

Universidade Federal de Juiz de Fora

Campus Universitário - Bairro Martelos

CEP 36036-330 - Juiz de Fora (MG)

E-mail: orlando@fbio.ufjf.br ou ovsousa@uol.com.br

\section{Caracterização química do óleo essencial de Hypericum brasiliense Choisy}

\author{
Carvalho, E.S.; Ferreira, J.L.P.; Arcenio, F.; Rocha, L.*; \\ Sharapin, $\mathbf{N}$.
}

Laboratório de Tecnologia de Produtos Naturais, Faculdade de Farmácia, Universidade Federal Fluminense

\section{Resumo}

Hypericum brasiliense Choisy, planta da família Guttiferae, ocorre principalmente nas regiões Sudeste e Sul do Brasil. Em trabalhos anteriores foram isolados e identificados nesta espécie, dentre outras classes de compostos, xantonas, floroglucinóis e flavonóides. Apesar da presença de óleos essenciais ser uma característica do gênero, ainda não há registros na literatura da composição química do óleo essencial desta espécie. Neste trabalho foi realizado o estudo químico da fração volátil de $H$. brasiliense visando identificar e quantificar as substâncias químicas presentes através da cromatografia em fase gasosa acoplada a espectrômetro de massas equipado com banco de dados.

\begin{abstract}
Hypericum brasiliense Choisy, plant of the Guttiferae family, occurs mainly in the regions Southeastern and South of Brazil. Xanthones, phloroglucinols, flavonoids and other compounds were isolated from this species. There are not registrations in the literature of the chemical composition of the essential oil of this species, in spite of the importance of these compounds in the chemistry of the genera. In this work, it was done the chemical study of the volatile fraction obtained by hidrodestilation of $H$. brasiliense and this fraction was analyzed by $\mathrm{CG} / \mathrm{MS}$.
\end{abstract}

A espécie Hypericum brasiliense Choisy, pertencente à tribo Hypericeae, sub-família Hyperocoideae, família Gutifferae $^{1}$, ocorre principalmente nas regiões Sudeste e Sul do Brasil $^{2}$ sendo encontrada no Estado do Rio de Janeiro no município de Nova Friburgo ${ }^{3}$. Popularmente é utilizada como adstringente, excitante, antiespasmódica e antiofídica ${ }^{3}$. Uma característica importante do gênero, encontrada na espécie em estudo, é a presença de glândulas foliares ${ }^{5}$, que algumas vezes não são visíveis externamente em folhas cutinizadas ou esclerotizadas ${ }^{6}$. Estas glândulas claras são formadas por espaços esquizóides intercelulares, revestidos de células que secretam um óleo essencial translúcido ${ }^{7,8,9,10}$. H. brasiliense é caracterizado por seu porte herbáceo, variando entre 0,5 e 1,0 m de altura, ramificado desde a base. O seu caule é cilíndrico na base e quandrangular na parte superior. Suas folhas opostas se mostram sésseis, glabras, linear-lanceoladas, atenuadas nas extremidades, com 1,0 a 2,0 cm de comprimento e contêm, como já mencionado, 